\title{
Designing Age Appropriate Engineering Outreach Activities
}

\author{
Martin Scherer and Mary Wells \\ Faculty of Engineering, University of Waterloo \\ mscherer@uwaterloo.ca and mawells@uwaterloo.ca
}

\begin{abstract}
For over twenty years, the University of Waterloo's Faculty of Engineering has been running outreach programming directed at elementary youth (ages 6 to 14) through its Engineering Science Quest (ESQ) summer camp program. All the activities are designed to be hands-on with the primary goal to increase participant's interest in Science, Technology, Engineering and Math (STEM). The camp develops themes, such as 'Outer Space' to help motivate activity development and provide practical examples to participants.
\end{abstract}

In 2010, the directors of ESQ modified the approach to develop camp outreach activities to ensure they were hands-on engaging activities related to science and engineering but also paid consideration to ensuring a secondary set of goals were met that considered the cognitive development of the children in the camp. The result was the development of hands-on outreach activities that engaged the participants in multiple ways.

The motivation behind the development of outreach activities with these secondary objectives in mind were based on observation of past successes and working knowledge of the target audience.

It is concluded that in order to make truly engaging and effective programming for elementary aged youth; activity developers should develop hands-on activities that incorporate both the interests of youth and their appropriate cognitive development stage. Using these methods in activity development will lead to an increase in success and a stronger impact of the programming.

Keywords: Outreach, Youth, Cognitive, Engineering, Themes

\section{INTRODUCTION AND BACKGROUND}

\subsection{Engineering Science Quest}

Waterloo Engineering outreach has been engaging youth through its Engineering Science Quest (ESQ) program for over 20 years. During this period the approach to its summer camp curriculum has gone through significant changes. Historic records indicate that in its early years, ESQ's approach was designed to replicate well known hands-on demonstrations. Over time, the ESQ camp program involved from this model to one that incorporated week-long themes.

The themes were chosen that would motivate activities and provide a common narrative for activities during the week. Examples of past themes include 'space', 'science of sports' and 'dinosaurs'. Instructors selected these themes and were encouraged to develop all activities to make use of these ideas. For example, building a geodesic dome out of rolled up newspaper would be called 'moon shelters', which tied into the aforementioned space theme. Themes were approved for camp use based on originality and relevance to the current youth interests. They were never to be used to hide the fact that program participants were engaging in science and engineering activities.

In 2010, the use of ESQ themes evolved in response to research conducted by the University of Waterloo Centre for Child studies which discussed how 4 and 5 year olds related to characters in stories being read to them [2]. While this age group is outside of the range that ESQ serves, it motivated a discussion on how themes are used, and that activities being run should be done in a way that is engaging to the age group in the camp in a deeper manner. As a result, in 2011, ESQ put renewed emphasis on theme selection, directing instructors to develop their programs with themes that served two purposes; the first to unify the camp experience, and the second to have activities connect to what has been referred to as the camp's meta-theme, see Table 1.

Table 1 Sample ESQ programs.

\begin{tabular}{|l|l|l|l|l|}
\hline $\begin{array}{l}\text { Age } \\
\text { Group }\end{array}$ & Grade & $\begin{array}{l}\text { Camp } \\
\text { Name }\end{array}$ & $\begin{array}{l}\text { Meta- } \\
\text { theme }\end{array}$ & $\begin{array}{l}\text { Example } \\
\text { theme }\end{array}$ \\
\hline $\begin{array}{l}6 \text { to } 7 \\
\text { years }\end{array}$ & 1,2 & Banting & $\begin{array}{l}\text { Story Book } \\
\text { Based }\end{array}$ & $\begin{array}{l}\text { Lost in a } \\
\text { Story }\end{array}$ \\
\hline $\begin{array}{l}8 \text { to } 9 \\
\text { years }\end{array}$ & 3,4 & Suzuki & $\begin{array}{l}\text { STEM in } \\
\text { My World }\end{array}$ & $\begin{array}{l}\text { How did this } \\
\text { get in my } \\
\text { lunch }\end{array}$ \\
\hline $\begin{array}{l}10 \text { to } 11 \\
\text { years }\end{array}$ & 5,6 & Newton & $\begin{array}{l}\text { Business of } \\
\text { Science }\end{array}$ & Earth Inc. \\
\hline $\begin{array}{l}12 \text { to } 14 \\
\text { years }\end{array}$ & $7,8,9$ & Edison & $\begin{array}{l}\text { Real } \\
\text { Science }\end{array}$ & $\begin{array}{l}\text { System } \\
\text { Shutdown }\end{array}$ \\
\hline
\end{tabular}


Further research into childhood cognitive development, particularly the work of Jean Piaget and Robbie Case, suggests why this approach has been a success.

\subsection{Cognitive Psychology}

The field of cognitive psychology focuses on all the mental activities associated with thinking, knowing, remembering and communicating [3]. Due to this broad range of foci, cognitive psychology is best described as the psychology of learning. Piaget's work focused on how a child develops through a series of stages is the basis for much of the research in this field. Two of his theories have a deep impact on how concepts should be taught. The first is the use of schemas, and the other is the four developmental stage model.

Schemas is the term Piaget used to explain the 'mental molds' that the brain builds to help people understand and interpret their experiences [3]. Throughout a lifetime an individual creates countless schemas that are altered through the interpretation and accommodation of knowledge. A classic example of this is as follows:

A book is read to a two year old about a cow, and notices the animal has four legs. The child creates a schema that all animals with four legs are cows. At the zoo, the same child sees a moose, and refers to it as a cow, as it has four legs and meets their schema. By calling the moose a cow, the child is trying to assimilate what they've seen to an existing schema. The parent corrects them and the child then accommodates their schema to being 'animals have four legs, and can be a cow or a moose'[3]

It is through challenging established schemas with new knowledge that we learn. In a STEM context, a child comes to camp knowing that when water is hot there is steam. Through activities, the schema of 'steam means hot water' can be expanded to 'steam is a sign of a change of state occurring'. Themes that tie to experiences activates this schema/assimilation dynamic.

Piaget also suggested that there are four distinct stages of cognitive development [3]. An additional column has been added to Table 2 to show which of Piaget's stage tie to ESQ camps.
Table 2 Piaget's development stages.

\begin{tabular}{|c|c|c|c|}
\hline Stage name & $\begin{array}{l}\text { Typical } \\
\text { age range }\end{array}$ & Description & $\begin{array}{l}\text { ESQ } \\
\text { Camps }\end{array}$ \\
\hline Sensorimotor & $\begin{array}{l}0 \text { to } 2 \\
\text { years }\end{array}$ & $\begin{array}{l}\text { Experiencing } \\
\text { the world } \\
\text { through } \\
\text { senses and } \\
\text { actions }\end{array}$ & none \\
\hline Preoperational & $\begin{array}{l}2 \text { to } 6 \\
\text { years }\end{array}$ & $\begin{array}{l}\text { Representing } \\
\text { things with } \\
\text { words and } \\
\text { images; using } \\
\text { intuitive } \\
\text { rather than } \\
\text { logical } \\
\text { reasoning }\end{array}$ & Banting \\
\hline $\begin{array}{l}\text { Concrete } \\
\text { operational }\end{array}$ & $\begin{array}{l}7 \text { to } 11 \\
\text { years }\end{array}$ & $\begin{array}{l}\text { Thinking } \\
\text { logically } \\
\text { about } \\
\text { concrete } \\
\text { events; } \\
\text { grasping } \\
\text { concrete } \\
\text { analogies and } \\
\text { performing } \\
\text { arithmetical } \\
\text { operations }\end{array}$ & $\begin{array}{l}\text { Banting } \\
\text { Suzuki } \\
\text { Newton }\end{array}$ \\
\hline $\begin{array}{l}\text { Formal } \\
\text { operational }\end{array}$ & $\begin{array}{l}12 \text { years to } \\
\text { adulthood }\end{array}$ & $\begin{array}{l}\text { Abstract } \\
\text { reasoning }\end{array}$ & $\begin{array}{l}\text { Newton } \\
\text { Edison }\end{array}$ \\
\hline
\end{tabular}

In response to criticism of Piaget's theories, Case and his compatriots, known as Neo-Piagetians, expanded on the model. Like Piaget, Case believed that there were four unique stages, but instead of progression being a result of age and schema building, one progressed through age and improved use of working memory. To Case, the storage space in someone's memory is a fixed size, but through improving use of working memory, this storage space could be used more efficiently [4].

Case believes there are four factors that contribute to the capacity of working memory [4]:

1. Myeliantion- The increase development of myelin sheaths leading to an increase in the efficiency of mental operations. The myelin sheath is the neural insulator that increases neural transmission.

2. Automatization through practice, operations become automatic. Automatization can free up resources that in turn can be used for other activities. 
3. Social experience and cultural variation- Social experience and cultural variation is seen as a major role in a child's development. Culture in this case can be broad, or the more immediate environment, such as the school classroom.

4. Development of central concept structuresresulting from automatization, children acquire central conceptual structures, networks of concepts that permit them to think about a range of situations in a more complex and advanced manner

Further, Case stressed that presenting information in an organized manner, would lead to an increased retrieval ability. Case's emphasis on the role of education and culture in the child's development is also a unique difference from Piaget. The role of culture in a child's development cannot be overstressed. The culture provides practice which helps the child refine, develop and automatize skills and information [4].

\subsection{Concerns about cognitive psychology}

While both Piaget and Case have identified stages through their research, it is important to remember that the ages they associate with these stages are only suggestions. A child will progress through the stages at a pace that may differ from these markers, but they will follow the order as presented.

Another danger with cognitive theory is the temptation to use the knowledge to try and accelerate children through the stages. Bjorklund and Green stress that cognitive immaturity is an important part of the developmental process[1]. What may be seen as immaturities, for example only seeing things as cause and effect, may exactly be what is exactly needed at that time to help the child understand their world, or other unseen issues.

The strength in these models is that it provides a framework to help design learning experiences. It is clear that taking a high level activity and simply 'dumbing it down' will not yield the best result, nor would running the activity at a high level, hoping that youth will 'rise to meet the challenge' being presented. There is a place for boundary pushing, but it is likely better results can be achieved by how the activity is framed.

\section{CONNECTING COGNATIVE THEORY TO ACTIVITIES}

These cognitive theories provide a strong means to explain why ESQ has seen success. Themes help activate the schema's that participants bring to the camp. A successful theme takes a camper's base knowledge and through the activities cause new knowledge to be assimilated causing held schemas to accommodate. Further, holding science programming outside of a traditional elementary classroom, where a theme is central to the décor and space triggers Case's third contribution to expansion of working memory; social experience and cultural variation. The meta-theme further adds more variation to activities. A camp theme for grade 5 and 6 students may be focusing on the science of the circus, but the meta-theme of 'business of science' asks youth to also think about what financial elements will play a role in the circus, and the science involved.

\subsection{Implementation}

Development and implementation of themes is done through an approval based process. Camp instructors are given a presentation of themes that address how they connect activities, what restrictions they have in selection (for example, themes cannot be repeated year-to-year), examples of past successful and not-so-successful themes. A discussion is held where instructors can ask clarifying questions and more detailed examples on the meta-themes are shared.

Instructors are then given time to brainstorm theme ideas and consult with each other and support staff to help refine their ideas. By the end of the week, instructors present three possible themes to the program directors and the full camp support staff. This selection group contains former instructors from previous years, which allows for the creation of continuity, and ensuring repeats of the immediate past are not repeated.

Over the following two months, instructors develop activities with these approved themes in the forefront of their minds. Through meeting regularly with support staff, activities are questioned for safety and guidance is provided to ensure strong connections to the meta-theme of the camp group. Instructors are given the freedom to have one or two activities exempt from the theme, on the basis that the activity would suffer from trying to be forced to fit the theme, and its content is too good to pass up.

\subsection{Examples of camp themes}

The following further discusses the earlier mentioned ESQ model, making connections with how the theme base approach engages elements of the discussed cognitive models. 


\section{Banting (ages 6 to 7 )}

The meta-theme for this group is 'Story book based'. All camps operate with a week long story that engages the participants in solving the problems the characters encounter through the use of STEM skills. In the example of 'Lost in the story', campers followed two characters, Mac and Molly, as they journeyed across the nursery rhyme kingdom. Along the way they helped characters solve their dilemmas, for example, helping Jack and Jill get water by using a pulley system.

By focusing on protagonist(s) that need to solve a clear, easy to understand challenge participants are to work past the problems that their own egotism at this stage may present.

In this camp, the majority of children are only starting to enter the concrete operational stage. Activities that call for multi-dimensional thinking or transformation are introduced with much guidance and explanation by the instructors.

\section{Suzuki (ages 8 to 9)}

As this group is becoming more aware of issues beyond themselves, and that multiple factors can inform their experiences, the meta-theme is 'STEM in my world'. An example of this being put into action is the camp theme of 'How did this get in my lunch?'. Through a series of questions and motivating activities, campers learned about the farm-to-table process food goes through.

This meta-theme allows youth to realize that STEM is present in many aspects of their daily life. Realizations are starting to be drawn that science and tools can have different roles depending the situation; the farmer doesn't only plant the seed, but he also are responsible for helping the food leave the farm once harvested.

\section{Newton (10 to 11)}

As the campers progress in both age and life experiences, more abstract thoughts can be brought into the camp room. With the meta-theme of 'Business of Science' the Newton age group represents the biggest jump ESQ experiences in desired outcomes by use of these meta-themes.

To discuss the business of science is to start to draw connections between STEM, research, entrepreneurship and business. Questions are asked about problems people have, how solutions can be marketed, and what role does science and research play in this process. This business of science model has been developed over the past five years and knowledge of how to effectively integrate this metatheme in a consistently effective manner has been developed and refined over time.

An example of this was the camp theme of Earth INC. where campers were tasked to find environmental friendly solutions to problems. Activities during the week explored different materials, providing 'research knowledge' about what they should and shouldn't use. Their fictional company stock price was impacted based on decisions they made after these activities. For example, Campers who used Styrofoam after an activity discussed the issues with disposing of the material, would see a negative impact on their stock price.

This meta-theme starts to bring in the abstract reasoning of the formal stage through its use of hypothetical-deductive reasoning. Full success with this theme also depends on the child to use skills and learned during the concrete-operational stage, such as their ability to think logically and understanding of transformations.

\section{Edison (ages 12 to 13)}

The oldest age group focuses starts to move away from traditional themes. Themes are no longer about making the activities relevant, but instead are used to provide a connecting element to all activities. For example a theme in this group may be 'System Shutdown' and explores the roles systems play in biology and engineering. With the meta-theme of 'real science' the goal is to provide activities that are held in teaching labs, and make use of scientific equipment. By using such space and tools campers began to envision themselves studying STEM topics at a secondary and post-secondary level.

Activities at this level demand the camper to be in the formal stage as accumulation of skills from across levels are used. Specifically the use of abstract and further use of hypothetical-deductive reasoning is key to the success of the programs at this level.

\section{DISCUSSION/CONCLUSIONS}

Internally this method has increased the ease of development, has led to more staff engagement with their work, and a greater variety of activities. From the camp organizers perspective, the quality of activities and instructor experience has increased.

Externally it is hard to judge the results of a program like ESQ. The temptation is to attempt to track students who come to the program for multiple years and see if they ultimately enroll in a STEM area at a post-secondary level. This would provide a good indication if they have 
chosen to make a career goal out of STEM. Privacy concerns, cost and logistics make it extremely difficult to track students in this manner.

The reputation of a program like ESQ is based on the elements of service and content. With the office structure of the program being relatively stable for the past several years, we can assume that quality of service has not changed dramatically. With this being ignored, we can judge the speed and how many spots fill annually in ESQ as a result of parents and youth connecting with content.

ESQ has filled close to $100 \%$ of its spots annually since this change occurred. Further the rate of enrolment has increased significantly. Figure 1 shows the registration rate for the camp once it opens in February. The average percentage fill for the three years after participants had experienced the change in curriculum, 2011-2013, versus the three years before, 2008-2010, show that what once took months to reach $50 \%$ of capacity in ESQ summer programs, now happens in less than 6 weeks. Anecdotally, it is safe to assume that the material has connected, and made a strong impression on both the parents and students in terms of their enjoyment of the ESQ camp experience.

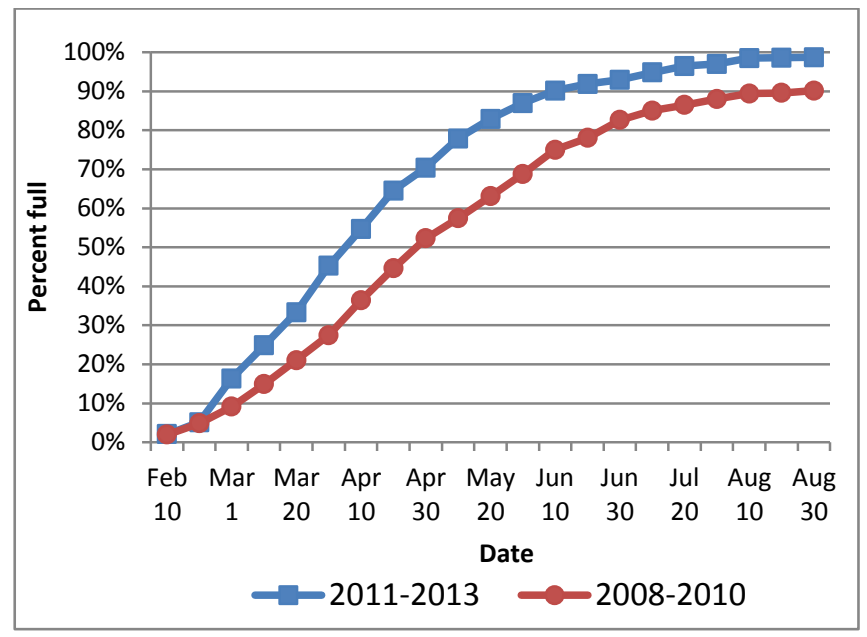

Figure 1 Average fill percentage of camp, before and after discussed changes.
This approach to themes and topics has spread from ESQ's summer programs and has influenced other aspects of its programming, such as in-school workshops and weekend programs, both being highly regarded by participants.

While programming was not designed with the end goal of tying into best practices from this area of cognitive research we have seen benefits since this has been acknowledge. There is a clear need to not only make early engagement with STEM fun, but also relevant to the child's educational level, social-cultural background and cognitive ability. Through providing activities that will lead to a level of success, you are strengthening not only the ability, but also the STEM identity of the child.

\section{Acknowledgements}

The authors wish to acknowledge the work of the Engineering Science Quest summer camp staff past and present. In particular the authors wish to acknowledge the work of the ESQ Coordinator, Caity Dyck.

\section{References}

[1] David F. Bjorklund and Brandi L. Green, "The Adaptive Nature of Cognitive Immaturity," American Psychologist, vol. 47, no. 1, pp. 46-54, 1992. Available as of March 28, 2014 from http://psycnet.apa.org/journals/amp/47/1/46.pdf

[2] Lusia D’Amato, “UW Study shows kids relate to stories that are read to them," Kitchener Record, Nov. 26 2010. Available as of March 28, 2014 from http://www.childstudies.uwaterloo.ca/pdf/RecordNov201 $\underline{0 . p d f}$

[3] David G. Myers, Psychology Ninth Edition in Modules. Holland, Michigan: Worth Publishers, 2010, 734 pp.

[4] John W. Santrock, Vera E. Woloshyn, Tiffany L. Gallagher, Tony Di Petta and Zipito A. Marini, Educational Psychology. Toronto: McGraw-Hill Ryerson, 2004, (1st ed.), 538 pp. 